\title{
Response consequences and Sidman avoidance behavior in the goldfish
}

\author{
GEORGE A. PINCKNEY, STATE UNIVERSITY OF NEW YORK \\ COLLEGE AT BROCKPORT, Brockport, N.Y. 14420
}

Goldfish were given a single 6- $h$ Sidman avoidance training session with a shock to shock ( $S-S)$ interval of $5 \mathrm{sec}$, and a response to shock $(R-S)$ interval of $2,5,10,15,20$ or 40 sec. Results indicated that performance was an inverted $U$-shaped function of $R-S$ interval, with highest terminal response rates being found with the $15 \mathrm{sec}$ and $20 \mathrm{sec} R-S$ groups.

Sidman avoidance behavior is characterized by the operation of two temporal parameters. One, the shock to shock (S-S) interval, determines the time which elapses between successive shocks in the absence of a response. The other, the response to shock (R-S) interval, determines the amount of shock free time which follows each response. Of the two, the R-S interval plays the more important role in the maintenance of Sidman avoidance behavior since successful avoidance responses must be made in the absence of shock during the R-S interval. It is during this interval that conditioned aversive temporal stimuli (CATS) develop, being initiated by the response which begins the R-S interval (Anger, 1963). As the R-S interval progresses these interoceptive stimuli become more aversive, reaching their maximal aversiveness just prior to the next shock. If, however, $S$ responds before the R-S interval elapses his response will be reinforced by a rapid reduction in the aversiveness of the situation.

The development of interoceptive temporal discriminations, then, plays a major role in the acquisition and maintenance of Sidman avoidance behavior and provides the comparative psychologist with an important area for cross-species investigations. At this time, little comparative parametric data are available since most of the work done to date has employed the rat as subject.

This paper presents the results of the first of a series of experiments designed to investigate the importance of response consequences on the development of stable Sidman avoidance behavior in the goldfish. It reports the effect of the length of the $\mathrm{R}-\mathrm{S}$ interval on response rate in the early stages of avoidance learning.

Method. Forty-two goldfish, Carassius auratus, served as Ss. They were obtained from a local dealer and were housed in 50 gal colony tanks prior to the experiment. The apparatus was an aquatic shuttlebox made from an 18 in. Betta splendens display tank divided into two compartments of equal size by a Plexiglas hurdle. A pair of photocells at each end of the hurdle, coupled with a binary relay circuit, monitored S's position and recorded each shuttle response. A $20 \mathrm{~V}$ ac shock was developed from a $110 \mathrm{~V}$ ac source passed through a variable resistor, and was delivered for a duration of $0.5 \mathrm{sec}$ through a pair of stainless steel electrodes set at each end of the shuttlebox. The entire apparatus was enclosed in a sound attenuating chamber which was ventilated by a fan and illuminated by a $15 \mathrm{~W}$ houselight.

Each $S$ was given a single $6 \mathrm{~h}$ training session. The S-S interval was $5 \mathrm{sec}$ for all Ss, with seven Ss each being randomly assigned to R-S intervals of $2,5,10$, 15,20 and $40 \mathrm{sec}$, respectively. The number of responses made and shocks received each hour were recorded by means of a Grason-Stadler print-out counter.

Results. The mean number of responses made by each of the six groups over the six hours of the experimental session are shown in Fig. 1. Analysis of variance revealed that the main effect of R-S interval was highly significant $(F=6.84 ; \mathrm{df}=5 / 36$; $p<.001)$, as was the interaction between R-S interval and Hours ( $F=6.83 ; \mathrm{df}=25 / 221 ; \mathrm{p}<.001$ ). The effect of hours, however, was not significant $(F=1.91 ; \mathrm{df}=5 / 221 ; \mathrm{p}>.05)$.

Analysis of variance of the number of shocks received by the six groups during the experiment indicated that the effects of R-S interval $(F=32.95 ; \quad$ df $=5 / 36 ; \quad p<.001)$, hours $(F=14.57$; $\mathrm{df}=5 / 221 ; \mathrm{p}<.001)$, and the interaction of R-S interval by hours $(\mathrm{F}=4.34 ; \mathrm{df}=5 / 221 ; \mathrm{p}<.001)$ were all highly significant.
As shown by Fig. 1, the three shorter R-S intervals did not facilitate avoidance behavior over the $6 \mathrm{~h}$ session. In fact, the $2 \mathrm{sec}$ interval resulted in somewhat of a "punishment" effect which resulted in the complete suppression of responding by the end of the session. In the absence of a response, $\mathrm{Ss}$ in this group were shocked every $5 \mathrm{sec}$; if they responded, however, they were shocked $2 \mathrm{sec}$ later. Since Ss were studied in a shuttlebox situation it was difficult for them to avoid the next shock by responding within that 2 sec period.

The $5 \mathrm{sec}$ group showed a high rate of response over the first half of the session, but the rate declined to its lowest point during the last hour. This high rate in the early stages of the session consisted of bursts of pseudo-escape responses and had little effect on the number of shocks received. The $10 \mathrm{sec}$ group showed a slight but steady decline in response rate over the $6 \mathrm{~h}$ of the session, and the number of shocks they received remained fairly constant from hour to hour. This may indicate that R-S intervals up to $10 \mathrm{sec}$ do not provide sufficient reduction in shock density to maintain avoidance behavior.

The response rates of the $15 \mathrm{sec}$ and $20 \mathrm{sec}$ groups were nearly identical, with the $20 \mathrm{sec}$ group benefitting most from this since they received $5 \mathrm{sec}$ more shock free time per response than did the $15 \mathrm{sec}$ group. The greatest reduction in number of shocks was shown by the $40 \mathrm{sec}$ group. Although they responded at a lower rate than the other groups they received fewer shocks than any other group. This is due in large part, of course, to the experimental situation which gave them $40 \mathrm{sec}$ of shock free time for each response.

Discussion. The results confirmed the findings of Behrend \& Bitterman (1963) that fish can learn to avoid shocks without the aid of exteroceptive warning stimuli. Regarding the effects of R-S intervals, the results were consistent with Leaf's (1966) finding that mean number of responses was an inverted U-shaped function of interval length. In Leaf's study, the highest level of responding in white rats was at the $10 \mathrm{sec}$ R-S interval, while the present data show higher response rates occurring with the 15 and $20 \sec R-S$

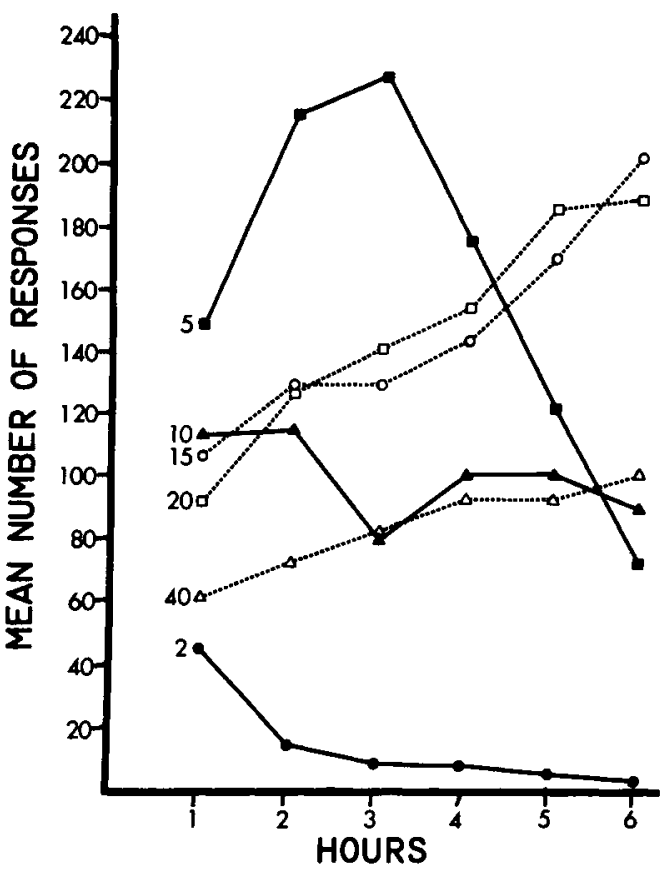

Fig. 1. Mean number of responses made by the six R-S groups during each of the $6 \mathrm{~h}$ of the experiment. R-S interval is shown at the $1 \mathrm{~h}$ point on each curve. 
intervals. These may be species differences or, more probably, are reflections of the different responses studied. Leaf worked with lever pressing, while the present study involved a shuttlebox response. These data are in agreement with another of Leafs findings: that the number of shocks received was a monotonic decreasing function of R-S interval length.

It must be pointed out that these data reflect behavior during initial stages of acquisition only, and give little insight into the behavior of these groups at asymptotic levels of performance. No data are available at present which reflect on this stage of responding in fish. Behrend \& Bitterman (1963) studied the behavior of goldfish for 20 days, but limited their observations to $20 \mathrm{~min}$ periods on each day of their experiment. More data on Sidman avoidance behavior in the goldfish are needed, particularly information on asymptotic level performance. A comprehensive study of inter-response times (IRTs) is also necessary before complete analysis of the development of CATS in this species can be made.

\section{REFERENCES}

ANGER, D. The role of temporal discriminations in the reinforcement of Sidman avoidance behavior. J. exp. Anal. Behav. Suppl, 1963, 6, 477-506. BEHREND, E. R., \& BITTERMAN, M. E. Sidman avoidance in the fish. $J$. exp. Anal Behav., 1963, 6, 47-52.

LEAF, R. C. Some effects of response consequences on Sidman avoidance acquisition. J. comp. physiol Psychol, 1966, 61, 217-220. 